\title{
A transformação da paisagem na favela objeto de regularização fundiária
}

\author{
Taisa Cintra Dosso,
} Jonathas Magalhães Pereira da Silva*

\begin{abstract}
Resumo O trabalho contribui para o debate referente à transformação da paisagem em favelas que ocorreram processos de regularização fundiária. A paisagem é entendida aqui como produto e processo de ocupação do território que revela os conflitos sociais do espaço. A transformação da paisagem urbana revela a profunda mudança nos costumes e hábitos nas relações espaço-tempo. A política pode contribuir para essas mudanças, manifestando-se na paisagem. Num espectro menor, na favela, quando ocorre a política pública de regularização fundiária, a paisagem reflete essa nova forma de ocupação do território, transformando aspectos morfológicos. A favela regularizada é refletida na paisagem em mutação, na paisagem transformada pelo processo.
\end{abstract}

Palavras-chave: paisagem, favela, transformação.

\section{La transformación del paisaje en la favela objeto de regularización del suelo}

Resumen El trabajo contribuye al debate de la transformación del paisaje en la favela en que ocurre la regularización del suelo. El paisaje, como producto y proceso de ocupación del territorio, revela los conflictos sociales del espacio. La transformación del paisaje en la ciudad revela el profundo cambio en las costumbres y hábitos en las relaciones espacio-tiempo. La política puede contribuir a estos cambios, manifestándose en el paisaje. En un espectro menor, en la favela, cuando ocurre la política pública de regularización del suelo, el paisaje refleja esa nueva forma de ocupación del territorio, transformándose. La favela regularizada se refleja en el paisaje cambiante, en el paisaje transformado por el proceso.

Palabras clave: paisaje, barrio bajo, transformación.
The transformation of the landscape into the favela that is subject to land regularization

\begin{abstract}
The work contributes to the debate of the transformation of the landscape in the favela where land regularization takes place. The landscape, as a product and process of occupation of the territory, reveals the social conflicts of space. The transformation of the landscape into the city reveals the profound change in habits and habits in space-time relationships. Politics can contribute to these changes, manifesting themselves in the landscape. In a smaller spectrum, in the favela, when the public politics of land regularization occurs, the landscape reflects this new form of occupation of the territory, transforming itself. The regularized favela is reflected in the changing landscape, the landscape transformed by the process.
\end{abstract}

Keywords: landscape, shanty town, transformation. 
0 presente trabalho busca contribuir para o debate referente à transformação da paisagem em favelas que ocorreram processos de regularização fundiária. A paisagem, como produto e processo de ocupação do território, revela os conflitos sociais do espaço. A política se manifesta na paisagem. Quando ocorre a política pública de regularização fundiária, a paisagem reflete essa nova forma de ocupação do território, transformando-se em seus aspectos morfológicos.

\section{Paisagem transformada: produto e processo de ocupação de território}

O conceito de paisagem foi mudando ao longo do tempo. Jean-Marc Besse (2014), em seu livro "Ver a terra: seis ensaios sobre a paisagem e a geografia", busca contribuir para essa perspectiva de transformação da paisagem.

Através da análise de textos que compreendem a paisagem desde a experiência de Petrarca de sua ascensão ao monte Ventoux, ou seja, a paisagem como algo que conduz, antes de tudo, à experiência de uma alteridade interior (BESSE, 2014, p 6), passando pela paisagem italiana na viagem de Goethe, que ao contrário, entende que a harmonia do mundo como paisagem desperta no sujeito a harmonia de suas faculdades internas (BESSE, 2014, 47), além de outras experiências como Brueghel, Alexander Von Humboldt, La Blache, Éric Dardel e Péguy, o livro evidencia a mutação conceitual de paisagem no tempo.

Um aspecto que merece ser destacado refere-se à concepção de paisagem segundo a geografia fenomenológica de Eric Dardel. A partir de Dardel, Besse aponta que

Antes então de qualquer experiência visual, antes de qualquer espetáculo, e dando ao espetáculo sua verdadeira dimensão, a paisagem é expressão, e, mais precisamente, expressão da existência. Ela é portadora de um sentido, porque ela é a marca espacial do encontro entre a Terra e o projeto humano. A paisagem é essencialmente mais mundo do que natureza, ela é o mundo humano, a cultura como encontro da liberdade humana com o lugar de seu desenvolvimento: a Terra. (BESSE, 2014, p. 92)

* Taisa Cintra Dosso é Advogada, Doutoranda em Arquitetura e Urbanismo pela Pontifícia Universidade Católica de Campinas, ORCID <https://orcid.org/00000003-0752-5849>. Jonathas Magalhães Pereira da Silva é Arquiteto e Urbanista, Professor da Pontifícia Universidade Católica de Campinas. ORCID <https://orcid.org/0000-0002-8186-9626>.

Neste contexto, a paisagem "permite manter uma relação viva entre o homem e a natureza que o envolve imediatamente. A paisagem desempenha o papel da "mediação", que permite à natureza subsistir como mundo para o homem" (BESSE, 2014, p. 82).

E sendo a ética uma maneira de tornar o mundo habitável, a geografia fenomenológica, segundo Dardel, que se coloca nesta perspectiva da "habitabilidade" do mundo, contribui para esta destinação ética do agir humano sobre a Terra." (BESSE, 2014, p. 95).

É nesse contexto de Dardel que a concepção atual de paisagem repousa. Ou seja, a paisagem é a manifestação dinâmica dos processos sociais do lugar. Vai além da simples 
representação, externando um produto decorrente de um processo. A paisagem é produto e processo de ocupação do território. Nas favelas, como no restante da cidade, a paisagem é resultante de um pacto. O que nos interessa na análise de territórios formados sem a mediação do estado é refletir a respeito do processo e de seus pactos.

Tomando a paisagem como resultante de pactos sociais, visando enfrentamentos contraditórios de diferentes grupos sociais:

A paisagem é entendida aqui como processo e produto de interação entre a sociedade e o suporte físico ambiental e, portanto, não se trata de algo estático. Entende-se, pois, que a paisagem está em constante transformação. Embora as ações antrópicas tenham um enorme poder em alterá-la, é necessário compreender que essa atuação sobre a paisagem não recebe forças consensuais; ela resulta de interesses e esforços bastante contraditórios e, além disso, não é apenas a sociedade humana que atua nessa transformação". (SILVA, p. 53)

Continua o autor:

Nossa argumentação é de que a paisagem não deve ser compreendida apenas como uma "composição" e sim como um processo que depende do suporte físico, portanto das condições ambientais, e principalmente da sociedade, composta por grupos sociais movidos por interesses conflituosos. Esse processo resulta em diversos produtos ao longo do tempo. Estes produtos são edifícios, jardins, parques, praças, ruas, bairros, distritos, vilas, cidades, plantações, minas, reservatórios, matas, florestas, campos, mangues, restingas, desertos, etc. Chamamos de produto, pois todos são criados pela tal "interação entre a sociedade e o suporte físico ambiental". Sua existência, porte e características irão resultar da ação dos agentes do território. Cabe destacar que este produto se altera quando as premissas socialmente construídas também se alteram. A paisagem do século XXI é diferente da paisagem do século XIX por conta de uma série de premissas e pactos estabelecidos pela própria sociedade. (SILVA, p.55-56)

Como conceito dinâmico e mutável, o modo como a paisagem é descrita está intimamente relacionado ao modelo de política pública adotado. A paisagem retrata a política, sendo pois uma das formas desta se manifestar. Na paisagem urbana, das cidades, esta relação é notória, evidente. Nas favelas, territórios formados pela ausência de políticas públicas, as paisagens resultam de pactos que ora são verbais e ora são documentados em instâncias "oficializantes" do pacto, como a associação de moradores.

1 Citado por Adriano Santos Soares, em "A paisagem como objeto de políticas públicas - o caso das favelas cariocas", In: Revista Geonorte, Edição Especial 3, v.7, N.1, p. 15-39, 2013, p. 20.
André-Louis Sanguin ${ }^{1}$ apresenta o conceito de paisagem política, afirmando que este é um conceito relativamente novo na geografia cultural e na geografia política, advindo de uma noção que resulta, principalmente, dos impactos e de adoção de uma ideologia e da autoridade política sobre a paisagem. No caso das favelas a "autoridade" pode não ser o estado e sim os grupos dominantes.

Os governos ou grupos dominantes moldam a paisagem através de políticas públicas ou de práticas estabelecidas pela tradição do lugar, porém não são os únicos a intervir. Há um "contra-poder", uma "contra-força" que também influencia na modelagem da 
2 Em seu texto, Ana Fani Alessandri Carlos coloca em aspa algumas passagens da obra de Clarice Lispector, "A cidade sitiada".

\footnotetext{
3 Adotando a noção de dimensão proposta por Betânia Alfonsin, Nelson Saule Júnior, leciona que "a dimensão da regularização fundiária compreende tanto a dimensão jurídica, que abrange o registro do título que reconhece o direito à moradia e confere a segurança jurídica de posse no Cartório de Registro de Imóveis, como a dimensão urbanística, que abrange a regularização do parcelamento do solo nos órgãos públicos competente, por meio de um plano de urbanização com normas urbanísticas específicas para este fim, bem como o registro do parcelamento do solo constante no plano de urbanização no Cartório de Registro de Imóveis". (SAULE JÚNIOR, 2004, p. 346-347).
}

paisagem. A paisagem política, segundo o autor, é a paisagem natural modelada por um grupo político. A política é o agente e o espaço natural é o caminho. A interação destes dois é representada pela paisagem política. (SANGUIN, 2013, p. 20).

A paisagem da cidade ou das favelas retrata pois a interação da sociedade e o suporte físico ambiental, o espaço urbano, estando portanto em constante transformação. Sobre a relação espaço-tempo, Ana Fani Alessandri Carlos (2004, p. 62) em "O espaço urbano" leciona que

A mudança nas relações espaço-tempo revelam a profunda mudança nos costumes e hábitos sem que as pessoas parecem se dar conta, pois as inovações são aceitas de modo gradual, quase despercebidas embrulhadas pela ideologia que aponta a degradação do cotidiano. A cidade onde tudo se transforma, onde os estilos se multiplicam passa a ser o lugar onde as pessoas "se arranjam para viver ou quem sabe sobreviver" criando constantemente, "formas de ganhar dinheiro". (...) O novo engole, incessantemente, as formas onde se escreve o passado e, com ele, seu estilo, a memória". Sem referencial o mundo, na busca incessante do novo, se transforma no instantâneo, "porque não havia tempo a perder, mesmo de noite a cidade trabaIhava fortificando-se e de manhã novas trincheiras estavam de pé" 2 .

A transformação da paisagem na cidade ou na favela revela a profunda mudança nos costumes e hábitos nas relações espaço-tempo. A política pode contribuir para essas mudanças. A favela regularizada é refletida na paisagem em mutação, na paisagem transformada pelo processo. Sua transformação ocorre pela chegada de um agente que passa a ter atuação dominante e portanto interfere nas correlações de forças locais.

\section{Regularização fundiária da favela}

Visto a dimensão da paisagem transformada, passa-se à análise da favela objeto de regularização fundiária. O conceito de regularização fundiária que prevalece é o proposto por Betânia de Moraes Alfonsin, pois compreende o instituto em questão como um processo interdisciplinar, dotado de dimensões.

Segundo a autora, a regularização fundiária foi assumida como uma política pública embebida de um propósito interdisciplinar de realizar, de forma conjunta e integrada as seguintes dimensões: a) regularização jurídica dos lotes; b) a urbanização/reurbanização do assentamento; c) a adequação com a legislação urbanística com a mudança do regime urbanístico aplicável a área e; d) o apoio e a motivação dos moradores para a auto-organização, o associativismo e a cooperação mútua em iniciativas que impliquem a melhoria das qualidade de vida da comunidade.

Importante salientar que não se está tratando de etapas de um processo, e sim de dimensões de uma política pública que se efetiva tanto melhor quanto mais o Poder Público tiver assimilado e implementado de forma complementar as dimensões identificadas. (ALFONSIN, 2000, p. 196-197). A partir dessas constatações, Betânia de Moraes Alfonsin (2007, p. 79) propõe o conceito ${ }^{3}$ de regularização fundiária

Regularização fundiária é um processo conduzido em parceria pelo Poder Público e população beneficiária, envolvendo as dimensões jurídica, urbanística e social de 
uma intervenção que, prioritariamente, objetiva legalizar a permanência de moradores de áreas urbanas ocupadas irregularmente para fins de moradia e, acessoriamente, promove melhorias no ambiente urbano e na qualidade de vida do assentamento, bem como incentiva o pleno exercício da cidadania pela comunidade sujeito do projeto.

Considerando esse enfoque interdisciplinar da regularização fundiária, com as dimensões jurídica, urbanística e social, a favela é o seu objeto principal. Alex Ferreira Magalhães, em sua obra "O direito das favelas" (2013), a partir de sua experiência nas favelas cariocas, busca o diálogo entre a produção teórica e o debate público contemporâneo a respeito da configuração das favelas e das políticas urbanas e elas direcionadas.

O autor adota o conceito pluridimensional de Betânia de Moraes Alfonsin e propõe o estudo das transformações no processo de regulação jurídica das favelas, entendido como o conjunto de mecanismos, estatais ou não, de diversas escalas, em que articulam no sentido de definir, fixar, divulgar, legitimar, impor e modificar as normas, regras ou parâmetros que visam controlar ou reger as atividades de apropriação, uso e aproveitamento do espaço.

O Observatório de Favelas, em "O que é a favela, afinal?" (SOUZA E SILVA, 2009, p. 96-97) apresenta uma Declaração própria, com o objetivo de contribuir para a formulação de um conceito de favela que abrigue a complexidade e a diversidade desse território no espaço urbano contemporâneo:

a) Considerando o perfil sociopolítico, a favela é um território onde a incompletude de políticas e de ações do Estado se fazem historicamente recorrentes. Portanto, as favelas são, de modo geral, territórios sem garantias de efetivação de direitos sociais, fato que vem implicando a baixa expectativa desses mesmos direitos por parte de seus moradores;

b) Considerando o perfil socioeconômico, a favela é um território onde os investimentos do mercado formal são precários, principalmente o imobiliário, o financeiro e o de serviços. Há, portanto, distâncias socioeconômicas consideráveis quando se trata da qualificação do tempo/espaço particular às favelas e o das condições presentes na cidade como um todo;

c) Considerando o perfil sócio-urbanístico, a favela é um território de edificações predominantemente caracterizadas pela autoconstrução, sem obediência aos padrões urbanos normativos do Estado. A favela significa uma morada urbana que resume as condições desiguais da urbanização brasileira e, ao mesmo tempo, a luta de cidadãos pelo legítimo direito de habitar a cidade;

d) Considerando o perfil sociocultural, a favela é um território de expressiva presença de negros (pardos e pretos) e descendentes de indígenas, de acordo com região brasileira, configurando identidades plurais no plano da existência material e simbólica. Superando os estigmas de territórios violentos e miseráveis, a favela se se apresenta com a riqueza da sua pluralidade de convivências de sujeitos sociais em suas diferenças culturais, simbólicas e humanas. 
A favela, como território com diversos perfis, se insere no espaço urbano contemporâneo. O conceito de espaço geográfico dado por Milton Santos (2008) como o espaço formado por um conjunto indissociável, solidário e também contraditório, de sistemas de objetos e sistemas de ações, não considerados isoladamente, mas como o quadro único no qual a história se dá, é identificado na favela.

No processo de formação da sociedade e com a ocupação dos espaços, o território surge através da formação socioespacial. O território é o espaço em que há uma tensão em razão da existência de relações sociais conflituosas. Já o lugar surge quando em determinado espaço há um valor, um significado.

No espaço, como conjunto de sistemas de objetos e sistemas de ações (SANTOS, 2008), é possível identificar um território, quando há uma tensão em razão das relações sociais, e também um lugar, quando há um valor, um significado.

Na favela, um espaço urbano contemporâneo, é possível identificar um território, com uma tensão entre as relações sociais tanto internas, entre os moradores, como externas, entre esses e o Estado e a sociedade. É possível também identificar um lugar, em que os moradores reconhecem um valor naquele espaço, atribuindo-lhe um significado muitas vezes afetivo.

É importante aqui também trazer o conceito de segregação social. Segundo Flávio Villaça (1998) "a segregação é um processo segundo o qual diferentes classes ou camadas sociais tendem a se concentrar cada vez mais em diferentes regiões gerais ou conjuntos de bairros da metrópole". A existência da favela é resultado de um flagrante processo de segregação sócio espacial nas cidades.

A noção dos conceitos de espaço, território, lugar e segregação sócio espacial faz-se necessária para auxiliar na compreensão da transformação da paisagem na favela objeto da regularização fundiária.

Havendo um território no espaço da favela, em que há a tensão entre as relações sociais existentes, a paisagem, como produto e processo de ocupação desse território, reconhece essa tensão, essas relações em que há conflitos de interesses.

Na favela esta tensão é bastante nítida tanto no que tange aos conflitos internos, de disputa de território, com moradias muito próximas umas das outras, quanto no que tange aos conflitos externos com o Estado e a própria sociedade, quando tendo em vista a reinvindicação do direito social à moradia, as ocupações ocorrem em lugares inadequados, como morros e áreas sujeitas à inundação ou próxima de áreas privilegiadas da cidade, acentuando a conflituosidade. A paisagem na favela revela essas conflitos.

Quando ocorre a política pública de regularização fundiária, os conflitos tendem a serem repactuados, cabendo destacar que a presença do Estado o processo acaba por reconhecer aquele território explicitando direitos e deveres. A paisagem resultante traduz essa nova forma de ocupação do território, e seus elementos morfológicos como: via, fachada, lote, quadra, etc. se transformam.

Questiona-se então o que se quer com a transformação da paisagem, explicando que: 
Certamente não haverá consenso. Alguns grupos defenderão como premissa a qualificação ambiental, de modo a não impactar negativamente nos processos de reprodução do capital. Outros terão como objetivo principal a promoção da equidade social. Outros se pautarão pela maximização da mais-valia urbana. Outros, pelo contrário, ainda tentarão recuperar esta mais-valia para o uso comum, por meio de instrumentos urbanísticos, enquanto outros priorizarão a defesa do ambiente. Cada postura provocará uma paisagem distinta. Portanto, a paisagem é consequência desses conflitos. (SILVA, p. 59)

Ousa-se dizer que quando a favela é regularizada, ocorre uma alteração, ainda que tímida, da "premissa". Ou seja, ao reconhecer a legitimidade do espaço, regularizando-o sob as dimensões jurídica, urbanística e social, o Estado repactua as relações de conflito, tanto sob o aspecto interno, entre os moradores, quanto sob o aspecto externo, com relação à sociedade. A premissa da disputa de território, embora ainda exista, é atenuada, cedendo espaço a uma premissa de maior tolerância e respeito ao direito à moradia digna de todas as pessoas.

\section{Considerações finais}

A conceituação a respeito da paisagem se alterou ao longo dos séculos, mudando a forma de se ver a terra. As favelas, num espectro menor de tempo, também passam por uma ressignificação e consequentemente por necessitar de um novo olhar onde a regularização urbanística cumpre um papel nessa transformação.

A transformação da paisagem na favela objeto da política de regularização fundiária, como produto, ocorre quando o processo de ocupação do território é reconhecido pelo Estado, legitimando-se, e, por consequência, atenuando as relações de conflito deste espaço complexo e multicultural dos assentamentos informais. A favela regularizada é refletida na paisagem em mutação, na paisagem transformada pelo processo.

\section{Referências bibliográficas}

ALFONSIN, Betânia de Moraes. O significado do Estatuto da Cidade para os processos de regularização fundiária no Brasil. In: Ministério das Cidades, Regularização fundiária plena: referenciais conceituais. Brasília: 2007.

Da invisibilidade à regularização fundiária: a trajetória legal da moradia de baixa renda em Porto Alegre - Século XX. (Dissertação - Mestrado em Arquitetura). Porto Alegre: UFRGS, Faculdade de Arquitetura, 2000).

BESSE, Jean-Marc. Ver a terra: seis ensaios sobre a paisagem e a geografia. Trad. Vladimir Bartalini. São Paulo: Perspectiva, 2014.

CARLOS, Ana Fani Alessandri. O espaço urbano: novos escritos sobre a cidade. São Paulo: Contexto, 2004.

CULLEN, Gordon. Paisagem urbana. Lisboa: Edicoes70, 2013.

FERNANDES, Edésio, ALFONSIN, Betânia. A lei e a ilegalidade na produção do espaço urbano. Belo Horizonte: Del Rey, 2003.

MAGALHÃES, Alex Ferreira. O direito das favelas. Rio de Janeiro: Letra Capital, 2013. 
NALINI, José Renato, LEVY, Wilson (Coord). Regularização fundiária. 2 ed. rev., atual e ampl. Rio de Janeiro: Forense, 2014.

SANTOS, Milton; SILVEIRA María Laura. O Brasil: território e sociedade no início do século XXI. $11^{\mathrm{a}}$ ed. Rio de Janeiro: Record, 2008.

SAULE JÚNIOR, Nelson. A proteção jurídica da moradia nos assentamento irregulares. Porto Alegre: Sergio Antonio Fabris Editor, 2004.

SILVA, Jonathas M. P. Premissas e critérios para a transformação da paisagem. In: Eduardo Barra,, Vera Regina Tângari, Mônica Bahia Schlee, Márcia Nogueira Batista. A vegetação nativa no planejamento e no projeto paisagístico. Rio de Janeiro: Riobooks, 2015. p. 53-65.

SOARES, Adriano Santos. A paisagem como objeto de políticas públicas - o caso das favelas cariocas, In: Revista Geonorte, Edição Especial 3, v.7, N.1, p. 15-39, 2013, p 20.

SOUZA E SILVA. Jailson (Org). O que é favela, afinal? Rio de Janeiro: Observatório de Favelas do Rio de Janeiro, 2009.

VILLAÇA, Flávio. Espaço Intra-Urbano no Brasil. Nobel/FAPESP, Lincoln Institute, São Paulo, 1998. 